\title{
Genomic amplification of 9p24.1 targeting JAK2, PD-L1, and $P D-L 2$ is enriched in high-risk triple negative breast cancer
}

\author{
Michael T. Barrett ${ }^{1}$, Karen S. Anderson ${ }^{2}$, Elizabeth Lenkiewicz ${ }^{1}$, Mariacarla \\ Andreozzi $^{1}$, Heather E. Cunliffe ${ }^{3}$, Christine L. Klassen ${ }^{4}$, Amylou C. Dueck ${ }^{5}$, Ann E. \\ McCullough ${ }^{6}$, Srikanth K. Reddy ${ }^{7}$, Ramesh K. Ramanathan ${ }^{8}$, Donald W. Northfelt ${ }^{8}$, \\ Barbara A. Pockaj ${ }^{4}$ \\ ${ }^{1}$ Department of Research, Mayo Clinic in Arizona, Scottsdale, Arizona, United States of America \\ ${ }^{2}$ Biodesign Institute, Arizona State University, Tempe, Arizona, United States of America \\ ${ }^{3}$ Department of Pathology, Dunedin School of Medicine, University of Otago, Dunedin, New Zealand \\ ${ }^{4}$ Division of General Surgery, Section of Surgical Oncology, Mayo Clinic in Arizona, Phoenix, Arizona, United States of America \\ ${ }^{5}$ Section of Biostatistics, Mayo Clinic in Arizona, Scottsdale, Arizona, United States of America \\ ${ }^{6}$ Department of Pathology and Laboratory Medicine, Mayo Clinic in Arizona, Scottsdale, Arizona, United States of America \\ ${ }^{7}$ Vanderbilt University, Nashville, Tennessee, United States of America \\ ${ }^{8}$ Division of Hematology-Oncology, Mayo Clinic in Arizona, Scottsdale, Arizona, United States of America \\ Correspondence to: \\ Michael T. Barrett, e-mail: Barrett.michael@mayo.edu \\ Keywords: 9p24. 1 amplicon, flow sorting, triple negative breast cancer, JAK2, PD-L 1 \\ Received: May 05, $2015 \quad$ Accepted: June 22, $2015 \quad$ Published: July 03, 2015
}

\section{ABSTRACT}

We used DNA content flow cytometry followed by oligonucleotide array based comparative genomic hybridization to survey the genomes of $\mathbf{3 2 6}$ tumors, including 41 untreated surgically resected triple negative breast cancers (TNBC). A high level $\left(\log _{2}\right.$ ratio $\left.\geq 1\right) 9$ p24 amplicon was found in TNBC (12/41), glioblastomas $(2 / 44)$, and colon carcinomas (2/68). The shortest region of overlap for the amplicon targets 9p24.1 and includes the loci for PD-L1, PD-L2, and JAK2 (PDJ amplicon). In contrast this amplicon was absent in ER+ $(0 / 8)$ and HER2+ $(0 / 15)$ breast tumors, and in pancreatic ductal adenocarcinomas (0/150). The PDJ amplicon in TNBCs was correlated with clinical outcomes in group comparisons by two-sample $t$-tests for continuous variables and chi-squared tests for categorical variables. TNBC patients with the PDJ amplicon had a worse outcome with worse disease-free and overall survival. Quantitative RT-PCR confirmed that the PDJ amplicon in TNBC is associated with elevated expression of JAK2 and of the PD-1 ligands. These initial findings demonstrate that the PDJ amplicon is enriched in TNBC, targets signaling pathways that activate the PD-1 mediated immune checkpoint, and identifies patients with a poor prognosis.

\section{INTRODUCTION}

There is an emerging recognition of the role of immune checkpoints in the pathogenesis of solid tumors [1]. Distinct inhibitory pathways serve to regulate $\mathrm{T}$ cell activation and function. These include the immune regulatory molecules PD-L1 and PD-L2 that limit the duration and the level of the T-cell response. Increased expression of these ligands of the immune checkpoint receptor PD-1 has been reported in human tumors
[2-4]. PD-1 is a CD28 and CTLA-4 homologue that is normally induced on activated $\mathrm{T}$ cells, but the chronic antigenic exposure in cancer may lead to high levels of PD-1 and T cell exhaustion [5]. Consequently PD-1 and its ligands are being investigated as candidate biomarkers for response to targeted immune checkpoint blockade in clinical trials of an increasing variety of tumors. Two PD-1 inhibitors, nivolumab and pembrolizumab, have been approved for clinical use in melanoma and are in clinical trials in other solid tumors [6]. In melanoma, the 
combination of nivolumab plus ipilimumab which targets the PD-1 homologue CTLA-4 was associated with a $>80 \%$ decline in tumor burden at 12 weeks in respondents and a 53\% overall response rate (ORR) [7]. More recent studies with a larger cohort of patients with untreated metastatic melanoma reported an ORR of $61 \%$ for the combination therapy with complete responses in $22 \%$ of patients [8]. However clinical studies have been limited by the lack of predictive biomarkers of disease response, the complexity of tumor genomes, and the degeneracy of the receptor/ligand interactions.

The Janus kinase 2 gene (JAK2) is one of four members of the JAK family (which includes JAK1, JAK2, JAK3 and non-receptor protein-tyrosine kinase 2 (TYK2) [9]. JAKs associate with the cytoplasmic portion of a variety of transmembrane cytokine and growth factor receptors important for signal transduction in hematopoietic cells. Receptor binding by extracellular ligand causes receptor multimerization and brings JAK proteins together to allow activation by transphosphorylation. Activated JAK2 has emerged as an important target in myeloproliferative disorders, and increasingly, in solid tumors [10]. Significantly JAK2 has been implicated in interleukin (IL)-6-dependent breast cancer stem cell self-renewal [11], and in both IL-6- and IL-8-dependent growth of triple-negative breast cancers (TNBCs) [12]. Pre-clinical studies have implicated JAK2 signaling as a mechanism of escape from targeted therapies in TNBC and as a promoter for the emergence of more invasive tumor cells [13]. Thus, JAK2 inhibitors are being evaluated in patients with breast and other solid tumors. However a case control study of 223 breast tumors reported an association between increased JAK2 mRNA levels and favorable prognosis [14], and a strong correlation between JAK2 mRNA levels with the presence of tumor-infiltrating lymphocytes (TILs). The protective effect of elevated JAK2 expression was not associated with increased JAK2 protein levels in the tumor epithelial cells. These observations suggest that therapeutic targeting of JAK2 expression may abrogate the potential benefits arising from an antitumor immune response. Thus the clinical significance of selective amplification and overexpression of JAK2 arising from the often highly aberrant genomic landscapes of solid tumors remains to be elucidated.

The PD-L1 and PD-L2 genes localize to 9p24.1 adjacent to JAK2 and there is emerging data that an amplicon targeting this 9p24.1 locus is present in lymphomas and a subset of EBV-positive gastric cancers $[15,16]$. Furthermore JAK2 has been shown to up-regulate the transcription of both PD-1 ligands and increase sensitivity to JAK2 inhibitors in a dose dependent manner [16]. We hypothesized that targeted amplification of 9p24.1 in tumor genomes would result in co-amplification of PD-L1, PD-L2, and JAK2, identify a distinct molecular subtype arising in multiple cancers, and provide a candidate biomarker for patients who may benefit from immune checkpoint targeted therapies. In order to address tissue and clonal heterogeneity in clinical samples we used DNA content based flow sorting to identify and purify distinct tumor populations in each tissue of interest [17-19]. There are well-established DNA staining based methods for isolating nuclei of aneuploid, tetraploid, and diploid neoplastic populations from solid tumor samples [20-23]. Individual populations of cells or nuclei can be objectively and quantitatively purified to greater than $95 \%$ purity for molecular analyses even in heavily admixed and sub-optimal clinical samples. We have developed and extensively validated flow cytometry based methodologies to study a wide variety of clinical samples including small needle biopsies, post treatment tissues, and formalin fixed paraffin embedded (FFPE) tissues with high definition genome assays such as oligonucleotide based array comparative genomic hybridization $(\mathrm{aCGH})$ and next generation sequencing NGS $[18,24]$.

To test our hypothesis we surveyed the genomes of 326 clinical samples representing pancreatic ductal adenocarcinomas (PDA) $(n=150)$, glioblastomas $(n=44)$, colorectal carcinomas $(n=68)$, and breast carcinomas $(n=64)$. Each tumor sample in this study was flow sorted prior to copy number analysis with oligonucleotide based aCGH. These data were then used to determine the prevalence of amplification of PD-L1, PD-L2, and JAK2 at chromosome 9p24.1 within each tumor type. The presence of this "PDJ" amplicon was then correlated with expression of JAK2 and the PD-1 ligands, and to clinical outcomes in a subset of patients.

\section{RESULTS}

We detected and sorted an aneuploid and/or a proliferating tumor fraction from each clinical sample in this study. These fractions were gated during sorting providing highly purified and objectively defined tumor populations from each sample for analysis. The tissues included triple negative breast cancer $n=41$, HER2+ breast cancer $n=15$, ER+HER2- breast cancer $n=8$, pancreatic adenocarcinoma $n=150$ (including 30 liver metastases), colorectal carcinoma $n=68$, and glioblastoma $n=44$. These included both fresh frozen and formalin fixed paraffin embedded (FFPE) clinical samples. The tumor cellularity prior to sorting varied extensively from less than $10 \%$ to greater than $70 \%$ across tissue types. The genomes of each sorted tumor cell population were interrogated with whole genome oligonucleotide based aCGH. Copy number aberrant intervals were identified and their genomic boundaries mapped using a step gram algorithm [25]. Amplicons were then ranked within each sample based on their fold change and their overall prevalence in tumor genomes. A recurring top ranked and high level $\left(\log _{2}\right.$ ratio $\left.\geq 1\right)$ amplicon that targeted 9p24.1 
was detected in 12/41 TNBCs, 2/68 colon carcinomas, and 2/44 glioblastomas (Figs. 1 and 2). In contrast this amplicon was absent in ER $+(n=8)$ and HER $2+(n=15)$ breast tumors, and in pancreatic ductal adenocarcinomas $(n=150)$. The shortest region of overlap (SRO) spanned $777 \mathrm{~kb}$ and included the PD-1 ligands PD-L1, PD-L2, and the Janus kinase 2 (JAK2) loci (Fig. S1). The height of this recurring amplicon included mean $\log _{2}$ ratios $>4$ consistent with amplification of genomic drivers such as HER2 and MYC described in breast cancer and other solid tumor genomes.

In order to determine the effect of the PDJ amplicon on JAK2, PD-L1, and PD-L2 expression we selected 31 TNBC samples, 16 of which were profiled in our copy number analysis, for qRT-PCR analysis. We used a pooled sample comprised of an unrelated normal breast, and individual TNBC, ER+, and HER2+ tumor tissues to generate a standard curve for assaying JAK2, PD-L1 and PD-L2 expression in our TNBC cohort. Tumors with a high level amplicon (4/16 TNBCs surveyed by qRT-PCR) had significantly higher expression of JAK2 and PD-L1 genes compared to those without the amplicon (Fig. 2). The latter included samples with low level copy number gains $\left(\log _{2}\right.$ ratio $>0$ and $\left.<1\right)$ at 9 p24.1 including increases of whole $9 \mathrm{p}$ arm and polysomy of chromosome 9 . In addition we identified another TNBC in the subset of 15 tumors without aCGH data with concurrent elevated expression of JAK2 and PD-L1 (Fig. S2). PD-L2 expression was also elevated in the presence of the PDJ amplicon however it did not reach statistical significance $(p<0.0645)$ in this preliminary study. These observations are consistent with studies showing that genomic amplification of 9p24.1 leads to coordinated overexpression of these genes in human tumors $[15,16]$.

Clinical data was available on 36 of $41(88 \%)$ of the TNBC patients that were flow sorted then profiled for copy number (Table 1). Patients with the high level PDJ amplicon $(n=8)$ were noted to have larger tumors (mean $3.9 \mathrm{~cm}$ vs. $1.9 \mathrm{~cm}, p=0.04$ ) and a higher incidence of lymph node metastases ( $75 \%$ vs. $26 \%, p=0.01)$. Lymphocytic infiltration was noted in 4 of the 36 patients, none of whom had the PDJ amplicon in their tumor
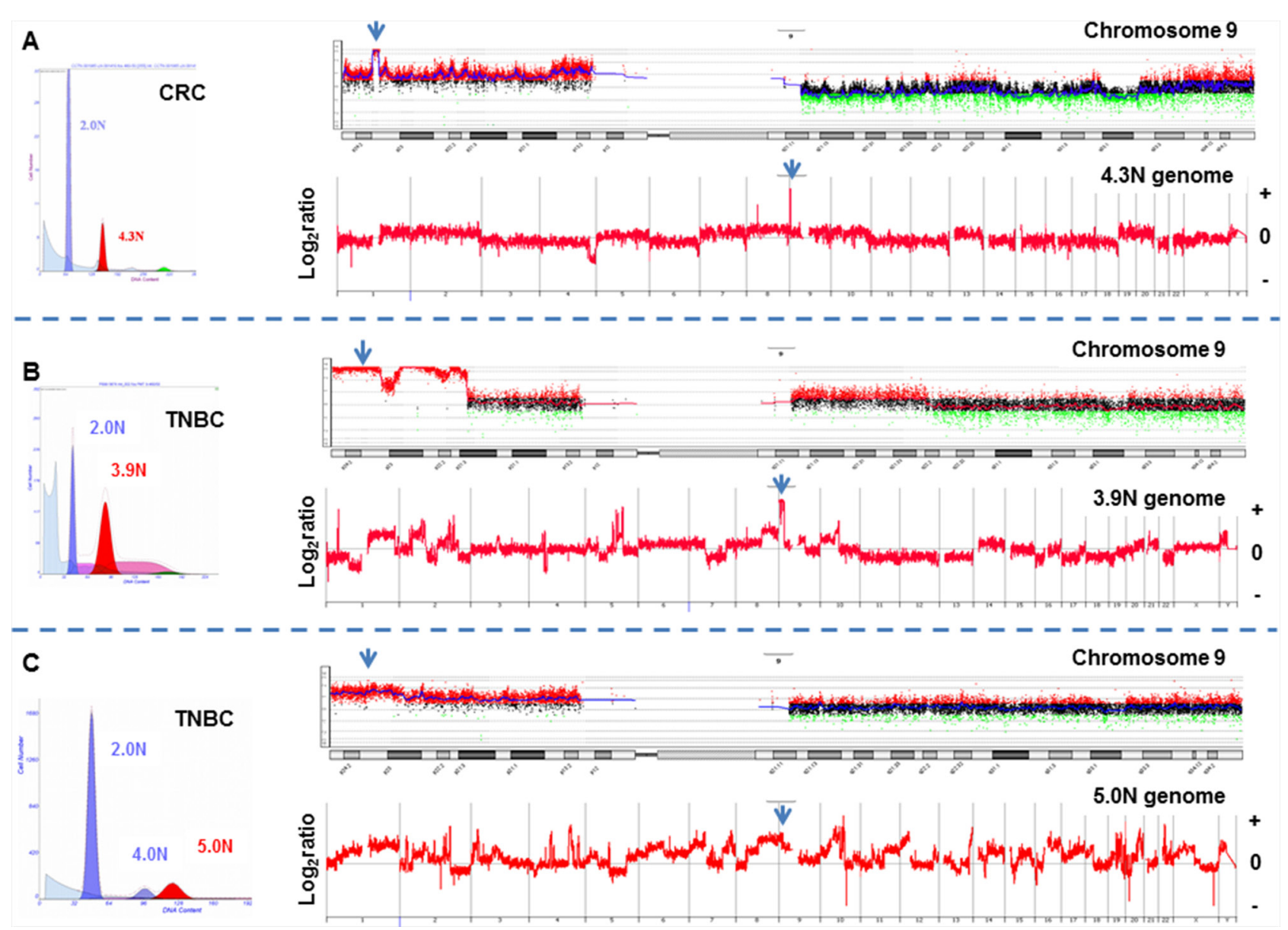

Figure 1: Whole genome and chromosome 9 aCGH plots of flow sorted tumor populations. A. Colorectal (CRC) and B-C. triple negative breast cancers (TNBC) with high level 9p24.1 amplicon. Amplicons were scored according to $\log _{2}$ ratios $>1$. Blue arrows denote $J A K 2$ locus. 

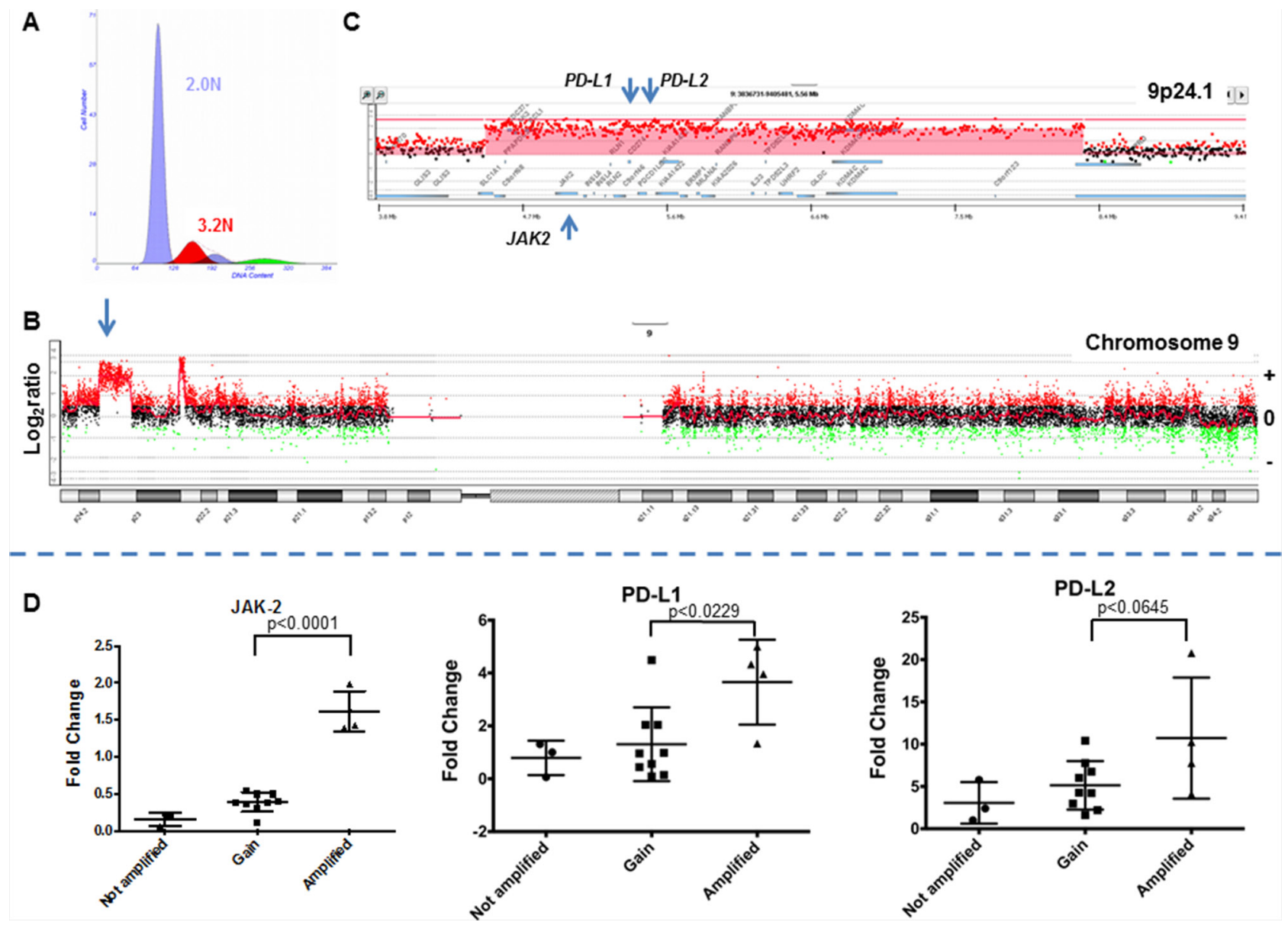

Figure 2: The 9p24 amplicon in a triple negative breast cancer genome. A. Flow histogram of sorted $3.2 \mathrm{~N}$ TNBC population from FFPE tissue. B. Chromosome $9 \mathrm{CGH}$ plot and detection of 9p24 amplicon. C. Gene specific view of amplicon. Red shaded area denotes ADM2 defined copy number aberrant region. D. Gene expression of JAK2, $P D-L 1$, and $P D-L 2$ in TNBC. Comparisons and correlations between the expression levels of $P D-L 1, P D-L 2$, and $J A K 2$ genes and copy number status of chromosome 9p24.1 were performed using an unpaired $t$ test and variation among and between groups were calculated using an ANOVA test (GraphPad Prism 6).

genome. Twenty nine of these $36 \mathrm{TNBC}$ patients received chemotherapy after definitive surgical therapy. The disease-free survival rate at 5 years was $25 \%$ in the PDJ amplified patients, and $66 \%$ in the unamplified patients $(p=0.005)$ (Fig. 3). Overall survival (OS) at 5 years was $25 \%$ in the PDJ amplified patients, compared with $69 \%$ in the unamplified patients $(p=0.004)$. Thus our preliminary results suggest that the presence of the PDJ amplicon defines a clinically significant subset of highrisk TNBC patients.

\section{DISCUSSION}

Studies in gastric cancer and in lymphomas have described a recurring 9p24.1 amplicon that includes PD-L1, PD-L2, and JAK2 [15, 16]. The presence of the amplicon was associated in a subset of each tumor type with distinct pathological and clinical features. Functional studies revealed that JAK2 is a transcriptional activator of both PD-1 ligands [16] and that sensitivity to JAK2 inhibition occurs in a dose-dependent manner [26]. Thus genomic amplification of 9p24.1 may provide a selective tumor cell dependent increase in both JAK2 and immune checkpoint signaling. In addition, copy number gains on chromosome 9 that include 9p24.1 and elevated expression of PD-L1 within tumor cells have recently been associated with substantial therapeutic activity in patients with advanced or refractory Hodgkin's lymphoma treated with the PD-1 inhibitor nivolumab [27]. Notably, two early phase I trials of PD-1/PD-L1 blockade (pembrolizumab or MPDL3280A) in TNBC have demonstrated overall response rates of $15-20 \%[28,29]$.

PD-L1 expression across multiple solid tumors varies significantly by tumor type and appears common in both tumor-infiltrating immune cells and in tumor cells $[4,30]$. Elevated PD-L1 expression from tumor infiltrating immune cells had a stronger association with clinical response than that observed with expression from the tumor cells [4]. Significantly elevated expression of JAK2 in the non-epithelial compartment of breast tumors 
Table 1: Comparison between patients with and without PDJ amplification

\begin{tabular}{|c|c|c|c|c|}
\hline & Not Amplified $(N=28)$ & Amplified $(N=8)$ & Total $(N=36)$ & $p$ value \\
\hline Age [years] & & & & $0.79^{1}$ \\
\hline Mean (SD) & $53.4(12.88)$ & $54.8(8.71)$ & $53.7(11.98)$ & \\
\hline Median & 54.0 & 53.5 & 54.0 & \\
\hline Range & $(29.0-78.0)$ & $(45.0-72.0)$ & $(29.0-78.0)$ & \\
\hline Tumor Size [cm] & & & & $0.04^{1}$ \\
\hline Mean (SD) & $1.9(0.86)$ & $3.9(3.88)$ & $2.4(2.11)$ & \\
\hline Median & 1.9 & 2.5 & 2.0 & \\
\hline Range & $(0.5-4.0)$ & $(0.4-11.0)$ & $(0.4-11.0)$ & \\
\hline Grade & & & & $0.63^{2}$ \\
\hline 1 & $1(3.6 \%)$ & $0(0 \%)$ & $1(2.8 \%)$ & \\
\hline 2 & $7(25 \%)$ & $1(12.5 \%)$ & $8(22.2 \%)$ & \\
\hline 3 & $20(71.4 \%)$ & $7(87.5 \%)$ & $27(75 \%)$ & \\
\hline $\begin{array}{l}\text { Lymphocytic } \\
\text { Infiltrates }\end{array}$ & & & & $0.21^{2}$ \\
\hline Missing & $10(. \%)$ & $2(. \%)$ & 12 & \\
\hline No & $14(77.8 \%)$ & $6(100 \%)$ & $20(83.3 \%)$ & \\
\hline Yes & $4(22.2 \%)$ & $0(0 \%)$ & $4(16.7 \%)$ & \\
\hline Lymph Nodes & & & & $0.01^{2}$ \\
\hline Missing & $1(\%)$ & $0(. \%)$ & 1 & \\
\hline Negative & $20(74.1 \%)$ & $2(25 \%)$ & $22(62.9 \%)$ & \\
\hline Positive & $7(25.9 \%)$ & $6(75 \%)$ & $13(37.1 \%)$ & \\
\hline Cancer Stage & & & & $0.04^{2}$ \\
\hline Missing & $1(. \%)$ & $0(. \%)$ & 1 & \\
\hline Stage I & $11(40.7 \%)$ & $1(12.5 \%)$ & $12(34.3 \%)$ & \\
\hline Stage II & $13(48.1 \%)$ & $3(37.5 \%)$ & $16(45.7 \%)$ & \\
\hline Stage III & $3(11.1 \%)$ & $4(50 \%)$ & $7(20 \%)$ & \\
\hline $\begin{array}{l}\text { Surgical } \\
\text { Treatment }\end{array}$ & & & & $0.70^{2}$ \\
\hline Missing & $9(. \%)$ & $2(. \%)$ & 11 & \\
\hline $\begin{array}{l}\text { Breast } \\
\text { Conservation } \\
\text { Therapy (BCT) }\end{array}$ & $8(42.1 \%)$ & $2(33.3 \%)$ & $10(40 \%)$ & \\
\hline Mastectomy & $11(57.9 \%)$ & $4(66.7 \%)$ & $15(60 \%)$ & \\
\hline Chemotherapy & & & & $0.10^{2}$ \\
\hline Neoadjuvant & $1(3.6 \%)$ & $2(25 \%)$ & $3(8.3 \%)$ & \\
\hline No & $4(14.3 \%)$ & $0(0 \%)$ & $4(11.1 \%)$ & \\
\hline Yes & $23(82.1 \%)$ & $6(75 \%)$ & $29(80.6 \%)$ & \\
\hline
\end{tabular}

(Continued) 


\begin{tabular}{|c|c|c|c|c|}
\hline & Not Amplified $(N=28)$ & Amplified $(N=8)$ & Total $(N=36)$ & $p$ value \\
\hline $\begin{array}{l}\text { Radiation } \\
\text { [Mastectomy only] }\end{array}$ & & & & $0.88^{2}$ \\
\hline Missing & $17(\%)$ & $4(. \%)$ & 21 & \\
\hline No & $5(45.5 \%)$ & $2(50 \%)$ & $7(46.7 \%)$ & \\
\hline Yes & $6(54.5 \%)$ & $2(50 \%)$ & $8(53.3 \%)$ & \\
\hline
\end{tabular}

${ }^{1}$ Two-Sample $T$-Test

${ }^{2}$ Chi-Square
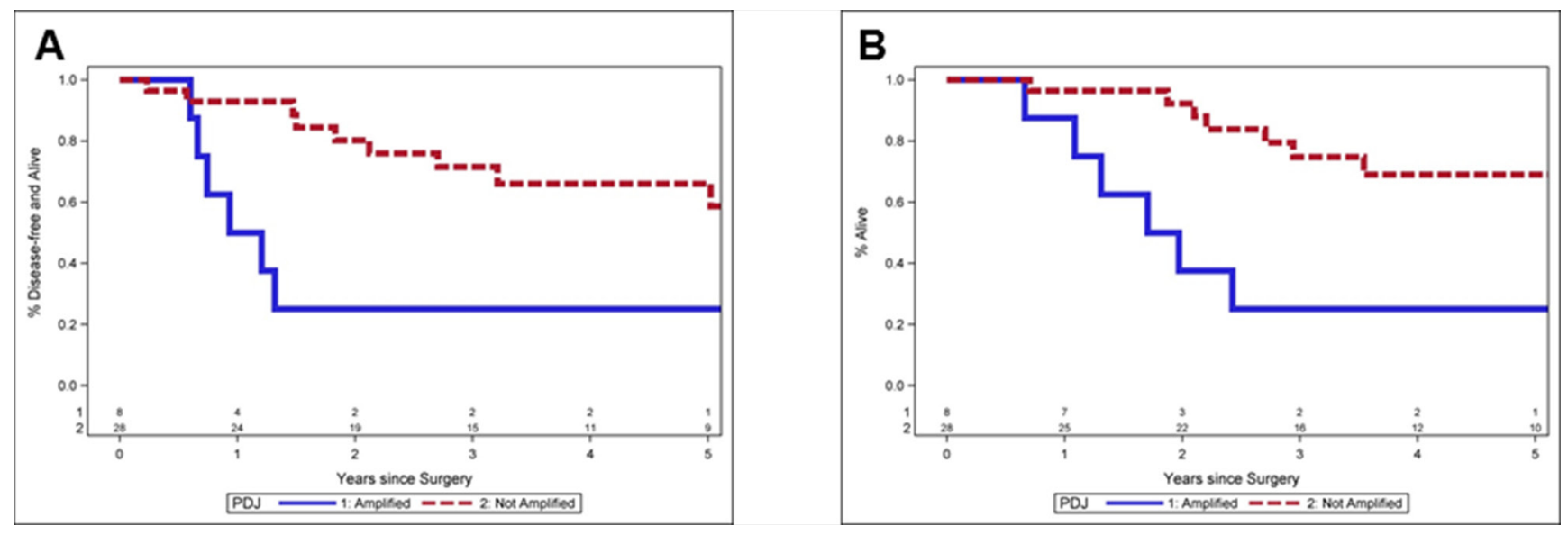

Figure 3: Clinical outcomes for TNBC patients with or without PDJ amplicon. A. Progression free survival. Lower diseasefree survival at 5 years $25.0 \%$ vs. $66.0 \%, p=0.005$. B. Overall survival. Lower overall survival at 5 years $25.0 \%$ vs. $69.0 \%, p=0.004$. Median follow up is 4.7 years (range $0.9-12.0$ years).

has been associated with a better prognosis and decreased risk of recurrence [14]. Thus an important clinical question is the role of a tumor cell driven elevation in JAK2 and PD-1 ligands versus increases arising from immune cells in solid tissue cancers $[6,27]$.

Previous in vitro studies of a 9p amplicon in a small panel of established breast cancer cell lines excluded JAK2, PD-L1, and PD-L2 loci from the SRO reported [31]. However JAK2 copy number levels assessed in bulk TNBC biopsies by targeted resequencing of a panel of 196 cancer associated genes have been reported to be elevated in residual disease post neoadjuvant chemotherapy. The JAK2 amplification was associated with poor regression free survival (RFS) and predicted poor OS in a subset $(\sim 10 \%)$ of TNBCs [32]. The prevalence of JAK2 amplification was noted to be higher in these post treatment TNBCs than reported for treatment naïve TNBCs in TCGA. The latter are based on single nucleotide polymorphism (SNP) array data of bulk tumor samples. Consequently it remained to be resolved whether JAK2 amplifications and the potential co-amplifications of PD-L1 and PD-L2 are present in untreated TNBCs, and whether genomic amplification at 9p24.1 may provide a biomarker for clinical outcome. Furthermore recent correlative studies with FISH based markers in lymphoma have proposed that even tumors with low level $9 p$ gains and chromosome 9 polysomy may benefit from PD-1 targeted therapies [27].

Our preliminary results with highly purified flow sorted clinical samples and an array platform designed for whole genome copy number measures suggest that the PDJ amplicon has a SRO that targets JAK2 and the PD-1 ligands, is enriched in a subset of TNBCs with poor outcomes prior to therapy, and is distinct from background genomic aberrations affecting chromosome 9. Given the coordinated overexpression of PD-L1, PD-L2, and JAK2, antagonists targeting PD-1 signaling and JAK2 inhibitors should be evaluated in the context of PDJ amplification. Thus we propose that the PDJ amplicon provides a candidate biomarker for identifying high-risk patients and for advancing emerging immunotherapies in TNBC. The absence of this amplicon in pancreatic adenocarcinoma samples and its relatively low frequencies in colorectal cancers and glioblastomas are consistent with relatively low response rates reported in these and other solid tumors when compared to TNBC $[33,34]$. However the presence and role of the PDJ amplicon in a smaller subset (2-5\%) of colorectal cancers, including primary and matching 
lymph node biopsies (Fig. S3), and glioblastomas warrants further investigation.

Given the highly aberrant genomic landscapes of TNBCs and other solid tumors, alterations that disrupt immune regulatory signaling pathways upstream or downstream of PDJ amplicon may provide additional biomarkers for this emerging class of therapies [35]. Studies in cell line models suggest that deletions in PTEN and disruption of AKT signaling can increase PD-L1 levels [36]. Our use of flow sorted clinical samples provides a robust objective method to detect somatic lesions targeting clinically actionable pathways [18, 24]. For example we detected focal deletions of PTEN in the tumor genomes of 5/12 PDJ positive TNBCs (Fig. 4 and Fig. S4). Future studies will incorporate flow sorted tissue samples and both copy number and next generation sequencing analyses to provide a more comprehensive and unbiased profile of the genomic landscapes of tumors with the PDJ amplicon. Of significant interest will be biopsies from patients enrolled in clinical trials with agents that target the PD-1 immune checkpoint. The ability to discriminate mutations and genomic lesions including the PDJ amplicon arising in the epithelial component of solid tumors and to comprehensively interrogate genomes in the pre and post adjuvant setting, regardless of tumor cell content, will be essential to understand clinical responses and to advance effective immunotherapies. These data will also be used to develop robust clinically relevant assays (e.g. targeted resequencing, FISH, IHC) to efficiently identify those patients with the PDJ amplicon. We propose that the PDJ amplicon in TNBC and other solid tumors represents a novel candidate biomarker with broad application for cancer research and for advancing personalized therapies for cancer patients.

\section{MATERIALS AND METHODS}

\section{Clinical samples}

TNBC, ER+, and HER2+ samples were obtained under approval from the Mayo Clinic Institutional Review Board prior to undertaking this study (IRB protocol 08-006579). Tumor specimens were obtained from formalin fixed paraffin embedded (FFPE) archived breast cancer samples obtained at the time of definitive surgical resection. All breast cancers underwent central pathologic review, and were evaluated by $\mathrm{IHC}$ for estrogen receptor (ER), progesterone receptor (PR), and by IHC +/- FISH for Her2/neu under CLIA/CAP guidelines. TNBC samples were also obtained from The Inflammatory Breast Cancer Research Foundation (IBCRF) Biobank. Samples were collected following informed consent by the IBCRF under approval of their IRB and their Medical Advisory Board. Additional flow sorted TNBC data was from a previous study of breast cancer genomes that was performed with informed consent and ethics committee approvals [37].
A

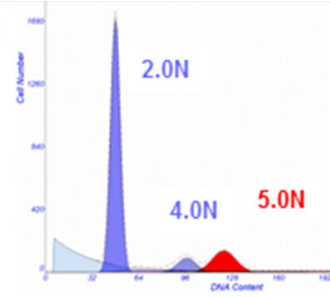

B

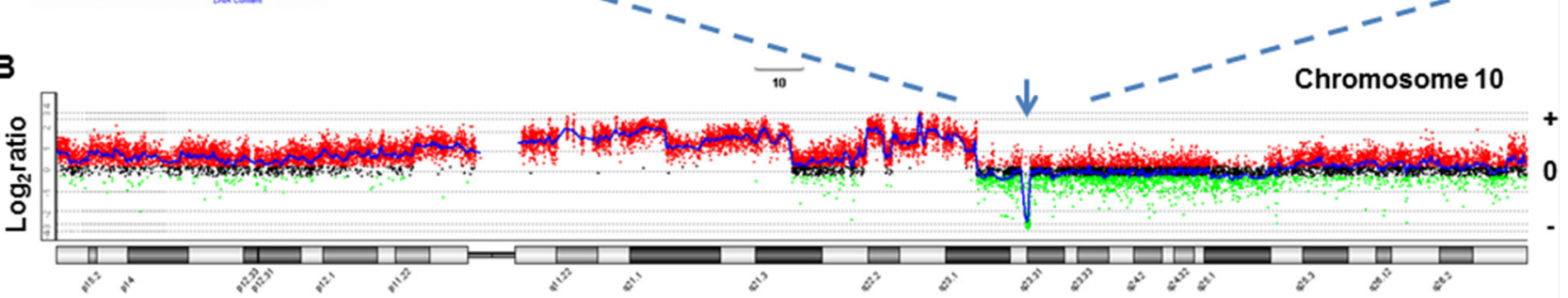

C

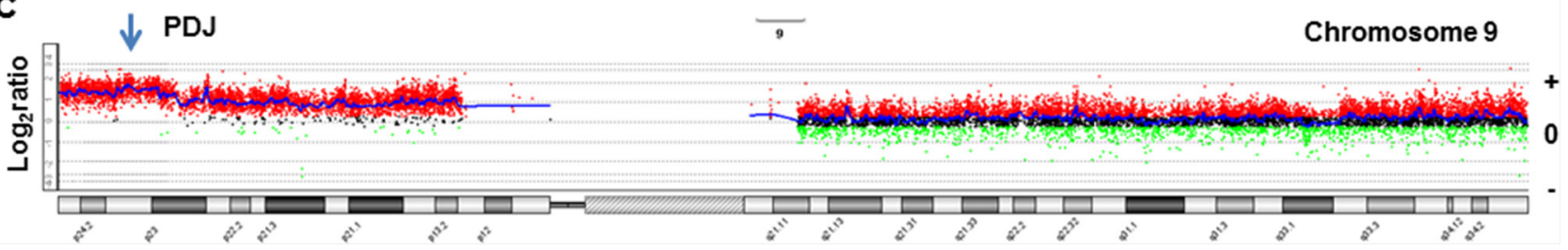

Figure 4: PTEN homozygous deletion in $\mathrm{PDJ}^{+}$triple negative breast cancer genome. A. Flow histogram of sorted 5.0N TNBC population from FFPE tissue. B-C. Chromosome 10 and chromosome 9 CGH plots. D. Gene specific view of PTEN homozygous deletion. Blue shaded area denotes ADM2 defined copy number aberrant region. 
PDA samples were from previous studies obtained under a WIRB protocol (20040832) for an NIH funded biospecimen repository (NCI P01 Grant CA109552), Stand up To Cancer clinical trials 2026001 and 2026003, and with approved consent of the Ethics Committee of Basel (252/08, 302/09).The glioblastoma samples were collected for another previous study with informed consent from patients at the Neurosurgery Department of the Centre Hospitalier in Luxembourg (CHL) [38]. Samples were approved for study by the National Ethics Committee for Research (CNER) of Luxembourg. In all cases written consent was obtained. De-identified colon samples did not qualify as human subjects according to guidelines administered by the Translational Genomics Research Institute (TGen) Office of Research Compliance and were collected under an institutional blanket exemption as part of different research initiatives and from the Cooperative Human Tissue Network (CHTN).

\section{FFPE sample preparation}

Prior to sorting, excess paraffin was removed with a scalpel from either side of 40-60 um scrolls then processed according to our published methods [24]. Briefly each sectioned piece was collected into individual microcentrifuge tubes then washed three times with $1 \mathrm{ml}$ Xylene for 5 minutes to remove remaining paraffin. Each sample was rehydrated in sequential ethanol washes $(100 \% 5$ minutes $\times 2$, then $95 \%, 70 \%, 50 \%$ and $30 \%$ ethanol) and washed 2 times in $1 \mathrm{ml} 1 \mathrm{mM}$ EDTA pH 8.0. A $1 \mathrm{ml}$ aliquot of $1 \mathrm{mM}$ EDTA pH 8.0 was added to the samples and incubated at $95^{\circ} \mathrm{C}$ for 80 minutes to facilitate the removal of protein cross-links present in FFPE tissue. Samples were then cooled to room temperature for $\geq 5$ minutes, followed by addition of $300 \mathrm{ul}$ PBS pH 7.4 and gentle centrifugation for 2 minutes at $3.6 \times \mathrm{g}$. The supernatant was carefully removed and the pellet washed three times with $1 \mathrm{ml}$ PBS pH 7.4/0.5 $\mathrm{mM} \mathrm{CaCl}_{2}$ to remove EDTA. Each sample was digested overnight (6-17 hours) in $1 \mathrm{ml}$ of a freshly prepared enzymatic cocktail containing 50 units/ml of collagenase type 3, 80 units $/ \mathrm{ml}$ of purified collagenase, and 100 units/ml of hyaluronidase in PBS $\mathrm{pH} 7.4 / 0.5 \mathrm{mM} \mathrm{CaCl}_{2}$ buffer. Following overnight digestion 500 ul NST buffer (146 mM NaCl, $10 \mathrm{mM}$ Tris- $\mathrm{HCl}, \mathrm{pH} 7.5,1 \mathrm{mM} \mathrm{CaCl}_{2}, 0.5 \mathrm{mM} \mathrm{MgSO}_{4}, 21 \mathrm{mM}$ $\mathrm{MgCl}_{2}, 0.05 \%$ bovine serum albumin, $0.2 \%$ Nonidet P40 (Sigma)) with 4, 6-diamindino-2-phenylindole (DAPI; $10 \mu \mathrm{g} / \mathrm{ml}$ ) was added to each sample to facilitate pelleting. Samples were centrifuged for 5 minutes at $3000 \times \mathrm{g}$, after which pellets were resuspended in $750 \mathrm{ul}$ of NST $/ 10 \%$ fetal bovine serum and then passed through a $25 \mathrm{G}$ needle 10-20 times. We used a single $50 \mu \mathrm{m}$ scroll from each FFPE tissue block to obtain sufficient numbers of intact nuclei for subsequent sorting and molecular assays.

\section{Flow cytometry}

Biopsies were minced in the presence of NST buffer and DAPI according to published protocols [23, 39, 40]. Prior to sorting each sample was filtered through a $35 \mathrm{um}$ mesh and collected into a $5 \mathrm{ml}$ Polypropylene round bottom tube. The mesh was rinsed with an additional $750 \mathrm{ul}$ of NST/10\% fetal bovine serum and placed on ice while processing remaining samples. The total volume in the tube for each sample was approximately $1.5 \mathrm{ml}$. An equal volume of $20 \mathrm{ug} / \mathrm{ml}$ DAPI was added to each tube to achieve a final concentration of $10 \mathrm{ug} / \mathrm{ml}$ DAPI for flow sorting with a BD Influx cytometer with ultraviolet excitation (Becton-Dickinson, San Jose, CA). The optimal settings for sorting FFPE samples with the Influx sorter were as follows: Drop formation was achieved with piezzo amplitude of 6-10 volts and a drop frequency of 30 khertz. The sort mode was set to purity yield with a drop delay of 31.5-32. Sheath fluid pressure was typically 17-18 psi with a 100 um nozzle. For single parameter DNA content assays DAPI emission was collected at $>450 \mathrm{~nm}$. DNA content and cell cycle were then analyzed using the software program MultiCycle (Phoenix Flow Systems, San Diego, CA).

\section{DNA extraction}

DNA from sorted nuclei was extracted using an amended protocol from QIAamp ${ }^{\circledR}$ DNA Micro Kit from Qiagen (Valencia, CA). Briefly each sorted sample was resuspended in $180 \mathrm{ul}$ buffer ATL and $20 \mathrm{ul}$ proteinase $\mathrm{K}(20 \mathrm{mg} / \mathrm{ml})$ then incubated for 3 hours at $56^{\circ} \mathrm{C}$ for complete lysis. Samples were bound and washed according to QIAamp ${ }^{\circledR}$ DNA Micro Kit instructions, eluted into $50 \mathrm{ul}$ of $\mathrm{H}_{2} 0$, then precipitated overnight with 5 ul $3 \mathrm{M}$ sodium acetate and 180 ul 100\% EtOH. Each sample was then centrifuged for 30 minutes at $20,000 \times \mathrm{g}$, washed in $1 \mathrm{ml}$ of $70 \% \mathrm{EtOH}$ for 30 minutes at $20,000 \times \mathrm{g}$. The samples were carefully decanted and the DNA pellet was dried by speed vacuum then resuspended in a small volume (e.g. 10-50 ul) of $\mathrm{H}_{2} \mathrm{O}$ for final concentrations suitable for accurate quantitation.

\section{aCGH analysis}

DNAs were treated with DNAse 1 prior to Klenowbased labeling. High molecular weight reference templates were digested for 30 minutes while the smaller fragmented FFPE-derived DNA samples were digested for only 1 minute. In each case 1 ul of $10 \times$ DNase 1 reaction buffer and 2 ul of DNase 1 dilution buffer were added to $7 \mathrm{ul}$ of DNA sample and incubated at room temperature then transferred to $70^{\circ} \mathrm{C}$ for 30 minutes to deactivate DNase 1 . Sample and reference templates were then labeled with Cy-5 dUTP and Cy-3 dUTP respectively using a BioPrime labeling kit (Invitrogen, Carlsbad, CA) according to our published protocols [18]. All labeling reactions were 
assessed using a Nanodrop assay (Nanodrop, Wilmington, $\mathrm{DE}$ ) prior to mixing and hybridization to $\mathrm{CGH}$ arrays (Agilent Technologies, Santa Clara, CA) for 40 hours in a rotating $65^{\circ} \mathrm{C}$ oven. All microarray slides were scanned using an Agilent 2565C DNA scanner and the images were analyzed with Agilent Feature Extraction version 10.7 using default settings. The aCGH data was assessed with a series of QC metrics then analyzed using an aberration detection algorithm (ADM2) [25]. The latter identifies all aberrant intervals in a given sample with consistently high or low log ratios based on the statistical score derived from the average normalized log ratios of all probes in the genomic interval multiplied by the square root of the number of these probes. This score represents the deviation of the average of the normalized log ratios from its expected value of zero and is proportional to the height $\mathrm{h}$ (absolute average log ratio) of the genomic interval, and to the square root of the number of probes in the interval. All aCGH data in this paper have been deposited at the National Center for Biotechnology Information Gene Expression Omnibus (accession number in progress).

\section{Expression analysis}

Total RNA was extracted from one whole-tissue $50 \mu \mathrm{m}$ thick section using RNeasy FFPE RNA Isolation Kit (Qiagen). RNA quantification was performed using Qubit 2.0 fluorometer (Life Technologies) and Qubit RNA HS assay kit (molecular probes). Reverse transcription was carried out using SuperScript ${ }^{\circledR}$ VILO $^{\text {TM }}$ cDNA Synthesis Kit (Life Technologies) and 200 ng of RNA per reaction, with triplicate reactions performed for each sample [41]. Each of the 31 samples produced sufficient RNA yield and quality. Quantitative Real-Time PCR was performed for CD274, PDCD1LG2, and JAK2 (Hs01125301_m1, Hs01057777_m1 Hs00234567_m1, respectively; Life Technologies) with TaqMan ${ }^{\circledR}$ chemistry on the ABI Prism 7900HT (Applied Biosystems), using the standard curve method. Furthermore, two reference genes were used TFRC and MRPL19 (Hs00174609_m1, Hs00608519_m1, respectively; Life Technologies), previously selected as effectively normalizing for degradation of the FFPERNA. Target gene expression levels were normalized to the geometric mean of the two reference genes and normalized to a pool of RNAs prepared from a normal and from 3 FFPE breast tumors (TNBC, ER+, and HER2+). All statistical comparisons and correlations between the expression levels of $P D-L 1, P D-L 2$, and $J A K 2$ genes and copy number status of chromosome 9p24.1 were performed using an unpaired $t$ test and variation among and between groups were calculated using an ANOVA test (GraphPad Prism 6). The $p$-values $<0.05$ were considered significant.

\section{Statistical analysis}

Group comparisons used two-sample $t$-tests for continuous variables and chi-squared tests for categorical variables. Disease-free survival time was defined as the time from primary surgery to first local, regional, or distant recurrence or death regardless of cause. Overall survival analysis included all deaths as events regardless of cause. Disease-free and overall survival rates at 5 years were estimated using the method of Kaplan and Meier. Disease-free survival and overall survival were compared between groups using a log-rank test. Median follow-up was 4.7 years (range $0.9-12.0$ years). $P$-values $<0.05$ were considered statistical significant throughout.

\section{ACKNOWLEDGMENTS}

This study was supported by funding from the non-profit Desert Mountain Member's C.A.R.E. (Cancer Awareness through Research and Education), Carefree AZ, and from The Inflammatory Breast Cancer Research Foundation (IBCRF) RFA-IBC-90-10-2011.

\section{CONFLICTS OF INTEREST}

None.

\section{REFERENCES}

1. Ribas A, Tumeh PC. The future of cancer therapy: selecting patients likely to respond to PD1/L1 blockade. Clinical cancer research: an official journal of the American Association for Cancer Research. 2014; 20:4982-4984.

2. Gao Q, Wang XY, Qiu SJ, Yamato I, Sho M, Nakajima Y, Zhou J, Li BZ, Shi YH, Xiao YS, Xu Y, Fan J. Overexpression of PD-L1 significantly associates with tumor aggressiveness and postoperative recurrence in human hepatocellular carcinoma. Clinical cancer research: an official journal of the American Association for Cancer Research. 2009; 15:971-979.

3. Taube JM, Klein A, Brahmer JR, Xu H, Pan X, Kim JH, Chen L, Pardoll DM, Topalian SL, Anders RA. Association of PD-1, PD-1 ligands, and other features of the tumor immune microenvironment with response to anti-PD-1 therapy. Clinical cancer research: an official journal of the American Association for Cancer Research. 2014; 20:5064-5074.

4. Herbst RS, Soria JC, Kowanetz M, Fine GD, Hamid O, Gordon MS, Sosman JA, McDermott DF, Powderly JD, Gettinger SN, Kohrt HE, Horn L, Lawrence DP, Rost S, Leabman M, Xiao Y, et al. Predictive correlates of response to the anti-PD-L1 antibody MPDL3280A in cancer patients. Nature. 2014; 515:563-567.

5. Melero I, Gaudernack G, Gerritsen W, Huber C, Parmiani G, Scholl S, Thatcher N, Wagstaff J, Zielinski C, Faulkner I, Mellstedt $H$. Therapeutic vaccines for cancer: an overview of clinical trials. Nat Rev Clin Oncol. 2014; 11:509-24.

6. Topalian SL, Sznol M, McDermott DF, Kluger HM, Carvajal RD, Sharfman WH, Brahmer JR, Lawrence DP, Atkins MB, Powderly JD, Leming PD, Lipson EJ, 
Puzanov I, Smith DC, Taube JM, Wigginton JM, et al. Survival, durable tumor remission, and long-term safety in patients with advanced melanoma receiving nivolumab. J Clin Oncol. 2014; 32:1020-1030.

7. Wolchok JD, Kluger H, Callahan MK, Postow MA, Rizvi NA, Lesokhin AM, Segal NH, Ariyan CE, Gordon RA, Reed K, Burke MM, Caldwell A, Kronenberg SA, Agunwamba BU, Zhang X, Lowy I, et al. Nivolumab plus ipilimumab in advanced melanoma. N Engl J Med. 2013; 369:122-133.

8. Postow MA, Chesney J, Pavlick AC, Robert C, Grossmann K, McDermott D, Linette GP, Meyer N, Giguere JK, Agarwala SS, Shaheen M, Ernstoff MS, Minor D, Salama AK, Taylor M, Ott PA, et al. Nivolumab and Ipilimumab versus Ipilimumab in Untreated Melanoma. The New England journal of medicine. 2015; 372:2006-17.

9. Verstovsek S. Janus-activated kinase 2 inhibitors: a new era of targeted therapies providing significant clinical benefit for Philadelphia chromosome-negative myeloproliferative neoplasms. Journal of clinical oncology: official journal of the American Society of Clinical Oncology. 2011; 29:781-783.

10. Quintas-Cardama A, Kantarjian H, Cortes J, Verstovsek S. Janus kinase inhibitors for the treatment of myeloproliferative neoplasias and beyond. Nature reviews Drug discovery. 2011; 10:127-140.

11. Marotta LL, Almendro V, Marusyk A, Shipitsin M, Schemme J, Walker SR, Bloushtain-Qimron N, Kim JJ, Choudhury SA, Maruyama R, Wu Z, Gonen M, Mulvey LA, Bessarabova MO, Huh SJ, Silver SJ, et al. The JAK2/STAT3 signaling pathway is required for growth of CD44(+)CD24(-) stem cell-like breast cancer cells in human tumors. J Clin Invest. 2011; 121:2723-2735.

12. Hartman ZC, Poage GM, den Hollander P, Tsimelzon A, Hill J, Panupinthu N, Zhang Y, Mazumdar A, Hilsenbeck SG, Mills GB, Brown PH. Growth of triplenegative breast cancer cells relies upon coordinate autocrine expression of the proinflammatory cytokines IL-6 and IL-8. Cancer Res. 2013; 73:3470-3480.

13. Britschgi A, Andraos R, Brinkhaus H, Klebba I, Romanet V, Muller U, Murakami M, Radimerski T, Bentires-Alj M. JAK2/STAT5 inhibition circumvents resistance to PI3K/ mTOR blockade: a rationale for cotargeting these pathways in metastatic breast cancer. Cancer Cell. 2012; 22:796-811.

14. Miller CP, Thorpe JD, Kortum AN, Coy CM, Cheng WY, Ou Yang TH, Anastassiou D, Beatty JD, Urban ND, Blau CA. JAK expression is associated with tumorinfiltrating lymphocytes and improved breast cancer outcomes: implications for evaluating JAK inhibitors. Cancer immunology research. 2014; 2:301-306.

15. Comprehensive molecular characterization of gastric adenocarcinoma. Nature. 2014; 513:202-209.

16. Green MR, Monti S, Rodig SJ, Juszczynski P, Currie T, O'Donnell E, Chapuy B, Takeyama K, Neuberg D, Golub TR, Kutok JL, Shipp MA. Integrative analysis reveals selective 9p24.1 amplification, increased PD-1 ligand expression, and further induction via JAK2 in nodular sclerosing Hodgkin lymphoma and primary mediastinal large B-cell lymphoma. Blood. 2010; 116:3268-3277.

17. Evers L, Perez-Mancera PA, Lenkiewicz E, Tang N, Aust D, Knosel T, Rummele P, Holley T, Kassner M, Aziz M, Ramanathan RK, Von Hoff DD, Yin H, Pilarsky C, Barrett MT. STAG2 is a clinically relevant tumor suppressor in pancreatic ductal adenocarcinoma. Genome medicine. 2014; 6:9.

18. Ruiz C, Lenkiewicz E, Evers L, Holley T, Robeson A, Kiefer J, Demeure MJ, Hollingsworth MA, Shen M, Prunkard D, Rabinovitch PS, Zellweger T, Mousses S, Trent JM, Carpten JD, Bubendorf L, et al. Advancing a clinically relevant perspective of the clonal nature of cancer. Proc Natl Acad Sci U S A. 2011; 108:12054-12059.

19. Ibrahim SF, van den Engh G. Flow cytometry and cell sorting. Adv Biochem Eng Biotechnol. 2007; 106:19-39.

20. Glogovac JK, Porter PL, Banker DE, Rabinovitch PS. Cytokeratin labeling of breast cancer cells extracted from paraffin-embedded tissue for bivariate flow cytometric analysis. Cytometry. 1996; 24:260-267.

21. Rabinovitch PS. DNA content histogram and cell-cycle analysis. Methods Cell Biol. 1994; 41:263-296.

22. Barrett MT, Sanchez CA, Prevo LJ, Wong DJ, Galipeau PC, Paulson TG, Rabinovitch PS, Reid BJ. Evolution of neoplastic cell lineages in Barrett oesophagus. Nat Genet. 1999; 22:106-109.

23. Maley CC, Galipeau PC, Finley JC, Wongsurawat VJ, Li X, Sanchez CA, Paulson TG, Blount PL, Risques RA, Rabinovitch PS, Reid BJ. Genetic clonal diversity predicts progression to esophageal adenocarcinoma. Nat Genet. 2006; 38:468-473.

24. Holley T, Lenkiewicz E, Evers L, Tembe W, Ruiz C, Gsponer JR, Rentsch CA, Bubendorf L, Stapleton M, Amorese D, Legendre C, Cunliffe HE, McCullough AE, Pockaj B, Craig D, Carpten J, et al. Deep clonal profiling of formalin fixed paraffin embedded clinical samples. PLoS One. 2012; 7:e50586.

25. Lipson D, Aumann Y, Ben-Dor A, Linial N, Yakhini Z. Efficient calculation of interval scores for DNA copy number data analysis. J Comput Biol. 2006; 13:215-228.

26. Hao Y, Chapuy B, Monti S, Sun HH, Rodig SJ, Shipp MA. Selective JAK2 inhibition specifically decreases Hodgkin lymphoma and mediastinal large B-cell lymphoma growth in vitro and in vivo. Clin Cancer Res. 2014; 20:2674-2683.

27. Ansell SM, Lesokhin AM, Borrello I, Halwani A, Scott EC, Gutierrez M, Schuster SJ, Millenson MM, Cattry D, Freeman GJ, Rodig SJ, Chapuy B, Ligon AH, Zhu L, Grosso JF, Kim SY, et al. PD-1 Blockade with Nivolumab in Relapsed or Refractory Hodgkin's Lymphoma. N Engl J Med. 2015; 372:311-9.

28. Emens LA, Braiteh FS, Cassier P, DeLord J-P, Eder JP, Shen X, Xiao Y, Wang Y, Hedge PS, Chen DS, Krop I. Inhibition of PD-L1 by MPDL3280A leads to clinical 
activity in patients with metastatic triple-negative breast cancer. San Antonio Breast Cancer Symposium. (San Antonio TX) 2014

29. Nanda R, Chow LQ, Dees EC, Berger R, Gupta S, Geva R, Pusztai L, Dolled-Filhart M, Emancipator K, Gonzalez E, Houp J, Pathiraja K, Karantza V, Iannone R, Gause C, Cheng $\mathrm{J}$, et al. A phase Ib study of pembrolizumab (MK-3475) in patients with advanced triple-negative breast cancer. San Antonio Breast Cancer Symposium. (San Antonio TX) 2014.

30. Taube JM, Klein A, Brahmer JR, Xu H, Pan X, Kim JH, Chen L, Pardoll DM, Topalian SL, Anders RA. Association of PD-1, PD-1 ligands, and other features of the tumor immune microenvironment with response to anti-PD-1 therapy. Clin Cancer Res. 2014; 20:5064-5074.

31. Wu J, Liu S, Liu G, Dombkowski A, Abrams J, MartinTrevino R, Wicha MS, Ethier SP, Yang ZQ. Identification and functional analysis of 9p24 amplified genes in human breast cancer. Oncogene. 2012; 31:333-341.

32. Balko JM, Giltnane JM, Wang K, Schwarz LJ, Young CD, Cook RS, Owens P, Sanders ME, Kuba MG, Sanchez V, Kurupi R, Moore PD, Pinto JA, Doimi FD, Gomez H, Horiuchi $\mathrm{D}$, et al. Molecular profiling of the residual disease of triple-negative breast cancers after neoadjuvant chemotherapy identifies actionable therapeutic targets. Cancer Discov. 2014; 4:232-245.

33. Brahmer JR, Tykodi SS, Chow LQ, Hwu WJ, Topalian SL, Hwu P, Drake CG, Camacho LH, Kauh J, Odunsi K, Pitot HC, Hamid O, Bhatia S, Martins R, Eaton K, Chen S, et al. Safety and activity of anti-PD-L1 antibody in patients with advanced cancer. The New England journal of medicine. 2012; 366:2455-2465.

34. Topalian SL, Hodi FS, Brahmer JR, Gettinger SN, Smith DC, McDermott DF, Powderly JD, Carvajal RD, Sosman JA, Atkins MB, Leming PD, Spigel DR, Antonia SJ, Horn L, Drake CG, Pardoll DM, et al. Safety, activity, and immune correlates of anti-PD-1 antibody in cancer. The New England journal of medicine. 2012; 366:2443-2454.

35. Mittendorf EA, Philips AV, Meric-Bernstam F, Qiao N, Wu Y, Harrington S, Su X, Wang Y, Gonzalez-Angulo AM, Akcakanat A, Chawla A, Curran M, Hwu P, Sharma P, Litton JK, Molldrem JJ, et al. PD-L1 expression in triplenegative breast cancer. Cancer immunology research. $2014 ; 2: 361-370$.

36. Lehmann BD, Pietenpol JA. Identification and use of biomarkers in treatment strategies for triple-negative breast cancer subtypes. The Journal of pathology. 2014; 232:142-150.

37. Przybytkowski E, Lenkiewicz E, Barrett MT, Klein K, Nabavi S, Greenwood CM, Basik M. Chromosomebreakage genomic instability and chromothripsis in breast cancer. BMC Genomics. 2014; 15:579.

38. Stieber D, Golebiewska A, Evers L, Lenkiewicz E, Brons NH, Nicot N, Oudin A, Bougnaud S, Hertel F, Bjerkvig R, Vallar L, Barrett MT, Niclou SP. Glioblastomas are composed of genetically divergent clones with distinct tumourigenic potential and variable stem cell-associated phenotypes. Acta neuropathologica. 2014; 127:203-219.

39. Galipeau PC, Li X, Blount PL, Maley CC, Sanchez CA, Odze RD, Ayub K, Rabinovitch PS, Vaughan TL, Reid BJ. NSAIDs modulate CDKN2A, TP53, and DNA content risk for progression to esophageal adenocarcinoma. PLoS Med. 2007; 4:e67.

40. Rabinovitch PS, Longton G, Blount PL, Levine DS, Reid BJ. Predictors of progression in Barrett's esophagus III: baseline flow cytometric variables. Am J Gastroenterol. 2001; 96:3071-3083.

41. Piscuoglio S, Ng CK, Martelotto LG, Eberle CA, Cowell CF, Natrajan R, Bidard FC, De Mattos-Arruda L, Wilkerson PM, Mariani O, Vincent-Salomon A, Weigelt B, Reis-Filho JS. Integrative genomic and transcriptomic characterization of papillary carcinomas of the breast. Mol Oncol. 2014; 8:1588-1602. 